OPEN ACCESS

Edited by:

Paul M. W. Hackett,

University of Cambridge, UK

Reviewed by:

Erich Christian Fein

University of Southern Queensland,

Australia

Se-Kang Kim

Fordham University, USA

*Correspondence:

Aharon Tziner

atziner@netanya.ac.il

Specialty section:

This article was submitted to

Theoretical and Philosophical

Psychology,

a section of the journal

Frontiers in Psychology

Received: 22 November 2016 Accepted: 22 December 2016

Published: 09 January 2017

Citation:

Tziner $A$ and Levy S (2017)

Examination of Performance Appraisal

Behavior Structure.

Front. Psychol. 7:2075.

doi: 10.3389/fpsyg.2016.02075

\section{Examination of Performance Appraisal Behavior Structure}

\author{
Aharon Tziner $^{1 *}$ and Shlomit Levy ${ }^{2}$ \\ ${ }^{1}$ Netanya Academic College-Schools of Behavioral Studies and Business Administration, Neatly, Israel, ${ }^{2}$ Department of \\ Contemporary Jewish Studies, Hebrew University in Jerusalem, Jerusalem, Israel
}

The personality (dispositional) characteristics, attitudes, beliefs, and orientation of 498 managers and military officers toward performance appraisal and organization were collected in order to examine their structural relationships to raters' behavior, in terms of (a) mean appraisal ratings, (b) measures of performance dimensions discrimination, and (c) rate discrimination. A mapping sentence comprising a modality, a reference group, and an aspect (content) facet were used. The empirical results largely confirmed this definitional system. Moreover, a polarizing partition of the space into three regions-Self (rater), Ratee, and Organization/System-was found, possibly implying that these three considerations are equally proximal in determining rater behavior. Future directions for research are advanced.

Keywords: attitudes, beliefs, performance appraisal behavior, facet analytic approach, personality, mapping sentence, facet theory

\section{INTRODUCTION}

The rating process has come under much scrutiny in the performance appraisal literature. One of the main conclusions that assists us to understand the nature of that process is that both the appraisal system and its organizational context are critical elements that play a part in the eventual employee evaluation outcomes. These outcomes, in turn, impinge upon the employees' status in the organization and, indeed, on the productivity of the business concern (e.g., Cleveland and Murphy, 1992; Murphy and Cleveland, 1995; Murphy, 2008).

The organizational context covers many aspects of organizational life including (1) raters' personality traits, (2) their attitudes toward the organization, and (3) their beliefs concerning, and attitudes toward, the performance appraisal system. Empirical research has increasingly demonstrated how these dispositions influence raters' performance during the appraisal process (e.g., Tziner et al., 1998; Tziner and Murphy, 1999; Tziner et al., 2002).

\section{Rater Personality}

The literature abounds with evidence of the links between broad personality characteristics and behavior in organizations (e.g., Barrick and Mount, 1991; Tett et al., 1991). This body of literature assists us to understand how an employee's attributes and personality traits contribute toward job performance and interaction in groups, among other organizational behaviors. With respect to appraisals, we could expect the traits of conscientiousness and self-monitoring to play a significant role in shaping appraisers' rating behavior, acting both as a direct influence on rating, and as a moderator of the relationships between the rating context and rating behavior.

\section{Conscientious Raters}

Raters who are conscientious are generally dependable, rule-abiding, and diligent. Such conscientious raters are likely to set high standards of performance, duteousness, and motivation 
to excel on the job (Costa and McCrae, 1992); consequently, they are more likely to conduct their performance rating responsibilities with greater diligence. The result: efficient discrimination among performance appraisal dimensions and among ratees, and less inflation of ratings. Raters who display conscientiousness are less likely to be swayed by the rating context than their less conscientious peers. The possibility thus exists that conscientiousness moderates the relationships between rating context and rating behavior measures (Tziner et al., 2002).

\section{Self-Monitoring Raters}

High self-monitoring individuals examine and control their own behavior successfully. They are susceptible to interpersonal and situational cues and typically manifest a strong desire to maximize social approval and to minimize social disapproval (Jawahar and Stone, 1997). Thus, we might also posit that individual differences in self-monitoring are associated with differences in rating behaviors among appraisers. Since social acceptance is a critical factor, in an appraisal context, high self-monitors (in contradistinction to low self-monitors) can be expected to inflate ratings of their subordinates and to discriminate less among ratees and performance dimensions.

\section{Attitudes toward the Organization}

Previous studies have confirmed links between organizational climate and rating behavior (e.g., Tziner et al., 2001). In this study we examined, in particular, organizational citizenship, a concept which is defined here as employees' cooperative behavior that is discretionary (rather than compulsory); it is not formally rewarded, and it contributes to the smooth functioning of the organization (Organ, 1988). This “informal” employee behavior has important consequences in the workplace and, indeed, Bolino (1999) has demonstrated how two manifestations of organizational citizenship-employee initiative and proactive cooperation-enhanced organizational functioning. Since high organizational citizenship implies working to promote organizational performance, raters displaying this characteristic can also be expected to pursue their appraisals with greater care. This should manifest itself in less incidents of rating inflation and better discrimination among performance dimensions and ratees.

\section{Beliefs about the Appraisal System}

Research conducted by Murphy and Cleveland (1995) and later by Tziner and colleagues (e.g., Tziner et al., 1998; Tziner and Murphy, 1999; Tziner et al., 2002), have borne out the supposition that raters' beliefs about performance appraisal systems are likely to affect their ratings. In particular, raters' beliefs about their ability to carry out the task of performance appraisal (selfefficacy), and the way in which performance appraisals are used in the organization, are important determinants of rating behavior.

\section{Self-Efficacy}

Raters differ in self-efficacy, their concern regarding their competencies with respect to possessing the requisite knowledge, tools, and professional skills with which to appraise their subordinates' performance accurately. In this respect, appraisers are less likely to discriminate among rating dimensions when they feel they lack the information or skills to rate accurately (Tziner et al., 2002).

The way in which appraisers regard themselves in this respect is also likely to play a motivational role that affects both the amount of effort they apply to the task of appraisal and their behavioral choices during that process. Specifically, following Bandura's $(1977,1982)$ social learning theory, raters' low selfefficacy might induce raters to distort their ratings. Moreover, raters' negative self-perceptions are likely to engender insufficient motivation to come up with appraisals that are solidly grounded, well-documented, reliable, and accurate (Frayne and Latham, 1987). Such adverse consequences have led the researchers to indicate that, under such circumstances, the appraisal process is a futile exercise (Napier and Latham, 1986). In contrast, raters with a high level of self-efficacy might be expected to perform the appraisal task more conscientiously.

\section{Ways in Which Performance Appraisal Is Used}

A substantial body of research demonstrates that raters are more likely to be more motivated (Cleveland and Murphy, 1992), lenient (Cleveland et al., 1989; Murphy and Cleveland, 1991; Landy and Farr, 1992) and attentive (Steers and Lee, 1983), when they believe that appraisals are to be used to determine administrative rewards such as promotions or salary raises. In contrast, when ratings are used for feedback purposes, and thus have fewer concrete consequences, supervisors may be more likely to provide biased evaluations. For instance, Fried et al. (1992) demonstrated that when appraisers rated employees who had little experience on the job, or were known to engender low confidence levels in their supervisors and/or the appraisal system, the appraisers were prone to discriminate against these subordinates.

\section{Orientation to the Appraisal System}

Raters' attitudes toward their own work play a crucial part in the way appraisers function during performance evaluations. Some raters are comfortable with the system while others are distrustful and cynical. Raters who have confidence in the results of the appraisal will likely produce more accurate ratings than those who are negative or skeptical. Why, however, would raters adopt a negative attitude to what is, after all, a primary task in their job description?

First, we may cite research conducted by Bernardin and Orban (1985) regarding raters who believed that their colleagues in the organization were biasing their performance appraisals. They perceived the "rogue" appraisers as being too lenient, consequently, inflating their subordinates' ratings to increase the benefits accruing to their workers. As a result of this perception, and especially when the performance appraisals were used for administrative purposes, the initial raters were induced to act likewise and to distort the appraisal results.

Second, raters have been observed as being very uncomfortable when they evaluate subordinates' performance and provide them with feedback (Murphy and Cleveland, 1991, 1995). One consequence of this discomfort is the tendency to inflate the ratings and to avoid making distinctions among 
subordinates (Villanova et al., 1993). By giving uniformly high appraisals, it appears that the raters avoid the potentially unpleasant consequences of assigning high ratings to some subordinates and low ratings to others.

\section{FACET ANALYTIC APPROACH}

In the present study, we capitalized on the facet analytic approach to examine the structure of performance appraisal behavior. After Guttman (1959), this approach posits that the components of a researched issue can be defined formally. Accordingly, the content of a concept is broken down into components or "facets." We can thus say that a facet is a criterion or a rule to classify items comprising a given concept (Roazzi et al., 2015) and that when we define the structural configuration of a concept, we spell out all its facets, exhausting its content (Elizur, 1984; Tziner, 1987).

We see that this definitional facet approach requires a taxonomy or classification of the content universe under scrutiny. We can thus describe the facets as the most important properties or components of the concept domain (content). The facets, therefore, constitute a classification of the constituents (elements) of a concept's content, according to some rule (i.e., exclusive features).

We are also interested in a taxonomy of the responses of the respondents to the issue under scrutiny. These responses are connected in the form of a statement, called the mapping sentence, which reads like an ordinary sentence (Hackett, 2014). The mapping sentence is then submitted to an empirical investigation, which if substantiated, becomes a valid representation of the content domain. The mapping sentence also serves as the basis of the generation of a theory (Canter, 1985; Shye et al., 1994).

The most compelling evidence of whether the empirical structure of the relationship among the variables conforms to the hypothesized structure appears when the hypothetical topological structure is superimposed onto the SSA depiction. The SSA (Smallest Space Analysis) is the non-metric scaling procedure that portrays geometrically the matrix of intercorrelation among the variables (e.g., questionnaire items and psychological tests). The geometrical display is done so that the intercorrelation among variables, which constitute measures of similarity, are plotted in space by distances between pairs of points: the stronger the intercorrelation the closer will be the points from one another.

The examination of the SSA output begins with an inspection of the inter-correlations matrix. To the extent that the following conditions are fulfilled by all variables, positive or zero intercorrelations are expected to emerge ${ }^{1}$ :

1. Variables relate to a common object of exploration (i.e., they concern the same observation or content domain).

2. Variables have the same range of responses (e.g., " 5 "being very high to " 1 " being very low) and reflect the same direction

\footnotetext{
${ }^{1}$ This requirement was termed First Law. First Law is always concerned with the sign of correlation among variables. Second Law calls for an inspection of the relative sizes of correlations, which warrant regional hypothesis derivation.
}

(with low figures at one extreme of the range to indicate low preference or disagreement with a statement, and with high figures at the other extreme to indicate high preference or agreement with the statement).

3. The population of the respondents was not selected artificially, specific to the domain of inquiry.

The first principle to be applied is the principle of contiguity which states that the geometric space in the SSA outcome should be partitionable into regions that reflect the facets and their "structs" (i.e., components, elements). According to this principle, variables that share the same facet structs should be more highly correlated and thus closer together in multidimensional space than variables that do not share the same facet structs. For example, in study of the achievement motive, the three variables entitled "preference for tasks involving uncertainty"; "satisfaction with tasks involving uncertainty"; and "undertaking tasks involving uncertainty," shared the same "structuple" (i.e., a pair of two elements, each comprised in a different facet). Consequently, we would expect them to be closer to each other than to other variables in the space, an expectation that was, in fact, upheld by the empirical data.

Furthermore, the more similar the variables are to each other in terms of their facet structs, the higher their expected inter-correlations. The consequence of this principle is that an inverse relationship is predicted between (a) similarity of variable structuples and (b) their distance within the special representation of their correlations. Indeed, an inspection of the inter-correlation matrix in article reveals that most of the variables that share two structs have a markedly higher intercorrelation than those sharing only one struct.

The division of the structure into regions is accomplished through boundary curves introduced to aggregate the variables according to the structuples of the mapping sentence.

However, variables of a region do not always cluster together. In most studies, the variables employed are only a sample of all conceivable items in the domain of observation. Because they comprise points everywhere in a geometric representation, some variables at the edge of one region may correlate less with other variables of the same region than with certain variables at the edge of neighboring regions.

An important feature of SSA is its relative insensitivity to variations in variable sampling. Thus, two different selections of items from the same observation domain can be expected to result in their small spaces having identical partition patterns. This is true even though the correlation matrices are different. Different correlations lead to considerable variations in variable positioning from one sample to another. Hence, almost identical configurations in the SSA plots can correspond to two considerably different inter-correlation matrices.

\section{The Performance Rating Context}

The rating context factors (e.g., comfort with performance appraisal), rater personality factors (e.g., self-monitoring), and rating behaviors (e.g., the extent of discrimination among ratees) can be classified into three facets: modality of behavior 
(cognitive, affective, and instrumental); referent group (self, ratee, appraisal system); and aspect (context: personal, interpersonal, organizational). The classification of the present study's variables by the elements comprising these three facets is displayed in Table 1.

Using these content facets and their elements, we developed the following mapping sentence, which interrelates factors affecting rating behavior:

Rater (x) in an organization (y) who Facet A: Modality of behavior

displays a $\quad\left\{\begin{array}{l}\text { 1. Cognitive } \\ \text { 2. Affective } \\ \text { 3. Instrumental }\end{array}\right\}$ mode of behavior
Facet B: Reference group

in respect to $\left\{\begin{array}{l}\text { 1. Self (rater) } \\ \text { 2. Ratee } \\ \text { 3. Appraisal system }\end{array}\right\}$ in

Facet C: Aspect (content)

a

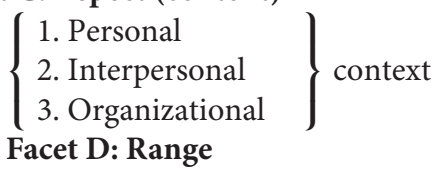
evidences $\longrightarrow \quad\left\{\begin{array}{l}\text { High (positive) } \\ \text { Low (negative) }\end{array}\right\}$ rating behavior.

The purpose of the present study was to examine this definitional framework empirically.

\section{METHODS}

Rating context factors, raters' conscientiousness, and raters' self-monitoring were measured by means of questionnaires, and were correlated with measures of rating level, discrimination among ratees, and discrimination among rating dimensions.

TABLE 1 | Classification of the study variables according to elements of the three facets.

\begin{tabular}{|c|c|c|c|}
\hline Variable & Modality & $\begin{array}{l}\text { Reference } \\
\text { group }\end{array}$ & $\begin{array}{l}\text { Aspect } \\
\text { (context) }\end{array}$ \\
\hline Confidence in the appraisal system & Affective & $\begin{array}{l}\text { Appraisal } \\
\text { system }\end{array}$ & Organizational \\
\hline Self-efficacy & Cognitive & Self (rater) & Personal \\
\hline Use of performance appraisal (between) & Instrumental & $\begin{array}{l}\text { Appraisal } \\
\text { system }\end{array}$ & Organizational \\
\hline Use of performance appraisal (within) & Instrumental & Ratee & Organizational \\
\hline Comfort with performance appraisal & Affective & Self (rater) & Interpersonal \\
\hline Organizational citizenship & Instrumental & Self (rater) & Organizational \\
\hline Conscientiousness & Cognitive & Self (rater) & Personal \\
\hline Self-monitoring & Cognitive & Self (rater) & Personal \\
\hline Rating level & Instrumental & I Ratee & Interpersonal \\
\hline Discrimination among ratees & Instrumental & Ratee & Interpersonal \\
\hline Discrimination among dimensions & Instrumental & Ratee & Organizational \\
\hline
\end{tabular}

\section{Participants and Procedure}

Questionnaires were distributed to 600 managers from several organizations and to 220 Israeli military officers. All the participants were responsible for appraising the performance of at least five subordinates. Usable data were obtained from 355 managers (59\%) and 143 officers (65\%). Of the managers, $77.7 \%$ were men and $22.3 \%$ women, whose average age was 43.54 years $(S D=10.01)$. The average tenure in the current company was 15.03 years $(S D=10.46) .11 .7 \%$ completed high school, $14 \%$ had some academic training, while $74.2 \%$ held a university degree in fields other than Business Administration. 87.9\% officers were male, and $12.1 \%$ were female; their average age was 32.31 years $(S D=7.02)$ and tenure in the military, 12.13 years $(S D=7.01)$. $12.6 \%$ completed high school, while $5.6 \%$ had some academic training, and $81.8 \%$ held a university degree.

\section{Instruments}

The instruments were administered in Hebrew and an equivalence of measures was achieved through back translation from English.

\section{Rater Personality (Conscientiousness)}

Ten items drawn from the NEO-Five Factors Inventory (Costa and McCrae, 1992) was employed to measure conscientiousness, whereby a high score on the scale reflects a high degree of conscientiousness. The internal consistency was alpha $=0.713$ $(M=3.66 ; S D=0.52)$ for managers, and alpha $=0.83(M=$ $4.91 ; S D=0.57$ ) for officers.

\section{Self-Monitoring}

Self-monitoring was gauged by means of five items garnered from an instrument developed by Gangestad and Snyder (1985). A high score on this scale indicates a high level of selfmonitoring. The internal consistency of self-monitoring measure was alpha $=0.62(M=4.42 ; S D=0.70)$ for managers and alpha $=0.63(M=3.83$; $S D=0.82)$ for officers.

In regard to all the above measures, it should be noted that they were calculated as average scores from the individual responses to the items comprising each variable.

\section{Attitudes toward the Organization (Organizational Citizenship Behavior)}

Organizational citizenship behavior was assessed using seven items from Podaskoff and MacKenzie's (1989) Organizational Citizenship Behavior Scale. A high score on this measure indicates strong organizational citizenship behavior. The internal consistency of the items used here was alpha $=0.81(i=5.07 ; S D$ $=0.74)$ for managers, and alpha $=0.80(M=4.99 ; S D=0.90)$ for officers.

\section{Beliefs about the Appraisal System (Self-efficacy)}

Eight items taken from scales developed by Napier and Latham (1986) were used to measure self-efficacy, specifically to assess the extent to which subjects believed that they possessed the appropriate competencies to appraise their subordinates. A high score indicated a high level of self-efficacy. The internal consistency of this measure was alpha $=0.70(M=4.67$; $S D=0.79)$. 


\section{Perceptions of Uses of Performance Appraisals}

Raters' perceptions concerning the uses of performance appraisal were measured using items drawn from the questionnaire devised by Cleveland et al. (1989), designed to produce two indices, namely: (a) perceptions of the extent to which performance appraisals are used by the organization to distinguish between ratees (between-person discrimination) for administrative purposes, including promotion, remuneration, and the identification of poor performers, and (b) perceptions of the extent to which appraisals are used to identify employees' strengths and weaknesses (within-person discrimination) for such purposes as performance feedback and the identification of individual training needs. Raters who evidenced high scores on these dimensions could be considered as perceiving that their appraisals were extensively used by management to achieve the goals for which the performance appraisals were originally proposed.

The first index consisted of 10 items, and yielded an internal consistency of alpha $=0.863(M=3.69 ; S D=0.91)$ for managers, and alpha $=0.91(M=3.65 ; S D=0.99)$ for officers. The second index consisted of eight items and produced an internal consistency of alpha $=0.69(M=3.09 ; S D=0.79)$ and alpha $=0.75(M=3.52 ; S D=0.68)$ for managers and officers, respectively.

\section{Comfort with Performance}

Eleven items from the Performance Appraisal Discomfort Scale (Villanova et al., 1993) were employed to measure comfort with performance We reversed the responses to the items, in order that a higher score would indicate a stronger degree of comfort with the performance appraisal and feedback. The internal consistency of this measure was alpha $=0.866(M=5.02$; $S D=0.73)$ for managers, and alpha $=0.87(M=4.93 ; S D=0.66)$ for officers.

\section{Orientation to Appraisal Systems}

Confidence in the appraisal system was measured using 11 items relating to political considerations taken from Performance Appraisal Questionnaire. The items inquire as to the extent to which political considerations play a role in the process of formulating performance ratings. A high score on this measure indicates that raters perceive the appraisal system to be heavily loaded with political manipulations and distortions and that the appraisers, consequently, harbor low levels of confidence in the appraisal process. The internal consistency of this measure, orientation to appraisal systems, was alpha $=0.82(M=3.43 ; S D$ $=0.76)$ for managers, and alpha $=0.81(M=3.60 ; S D=0.79)$ for officers.

\section{Rating Behavior Measures}

Each supervisor rated multiple subordinates (usually three or more) using a 12-item behavioral incident rating scale. The extent to which each behavior was exhibited by the ratee was registered on a 6-point scale ranging from "never"(1) to "always"(6). A high score indicates good performance. The coefficient alpha for these scales was 0.95 for officers and 0.88 for manager.

For each rater, three rating behavior measures were obtained, namely, (1) rating level, (b) discrimination among ratees, and
(3) discrimination among dimensions. Level of rating was represented by the overall mean of each rater's evaluations. $(M=4.57 ; S D=0.60)$. Following earlier studies of this nature, the index of ratee discrimination was derived from the standard deviation of the ratee means obtained from each rater (see Tziner et al., 2001; $M=0.94 ; 0.52$ ). Discrimination among dimensions was represented by the variability of the mean score assigned to each performance incident statement by each rater $(M=0.76$; $S D=0.36)$. It is worth noting that all the scales and measures of this study demonstrated reasonable psychometric qualities in a stream of previous publications (e.g., Tziner et al., 2001).

\section{RESULTS}

The correlation matrix was first computed, Table 2 displays the results.

Inspection of the correlations indicates that the general expectation that the more facet structs the variables share, the higher they will be correlated (according to the contiguity principle) is largely upheld. For example, rating level and discrimination among ratees share the same structuple: Instrumental, Ratee, Interpersonal. Therefore, each of these two variables should inter-correlate higher than either of them with variables with which they have no structs in common, such as self-efficacy, conscientiousness, or self-monitoring $(-0.40$ vs. $0.26,0.8,0.13,0.15,-0.2,0.19)$.

This matrix was then submitted to the SSA software (using a non-metric solution), which maps the variables as points in the Euclidean space of two dimensions. The geometrical configuration is presented in Figure 1.

The coefficient of alienation obtained was 0.104 , which can be considered a very good fit of the two-dimensional plot to the original inter-correlation matrix. The figure shows that variables sharing the same facet elements are positioned closer together in the configurative plot than variable that do not.

The division of the space is largely radial (polarizing), with one region consisting primarily of variable related to the self (rater), neighbored by a region of mostly ratee-associated variables, and a

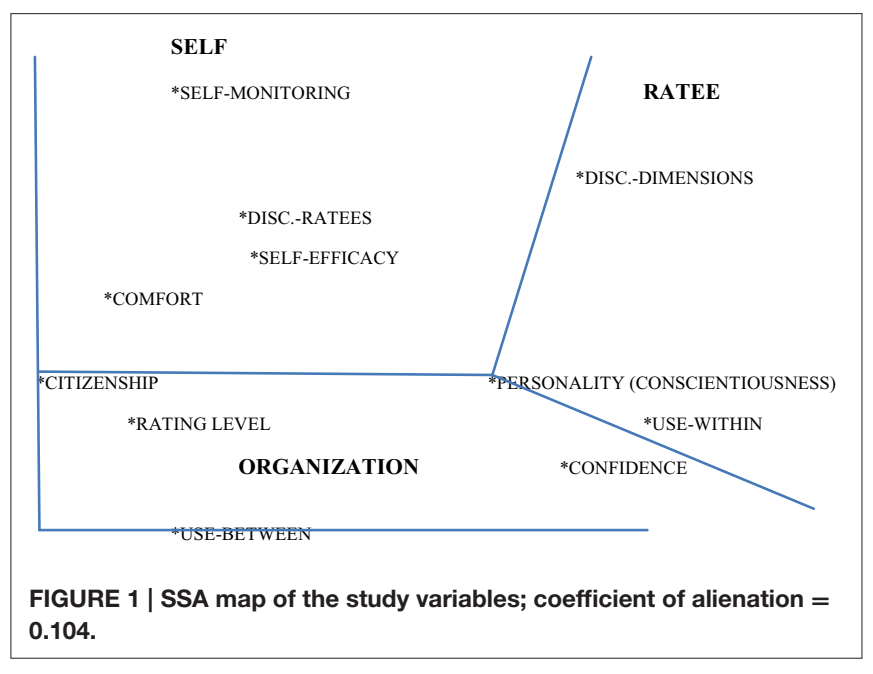


TABLE 2 | Correlations among study variables $(N=498)$.

\begin{tabular}{llccccccccccc}
\hline & $\mathbf{1}$ & $\mathbf{2}$ & $\mathbf{3}$ & $\mathbf{4}$ & $\mathbf{5}$ & $\mathbf{6}$ & $\mathbf{7}$ & $\mathbf{8}$ & $\mathbf{9}$ & $\mathbf{1 0}$ & $\mathbf{1 1}$ \\
\hline 1 & Confidence & 100 & -07 & -11 & 62 & -18 & -02 & 10 & -35 & -23 & 05 & 12 \\
2 & Self-efficacy & -07 & 100 & 22 & 13 & 30 & 21 & 41 & 40 & 26 & 08 & 17 \\
3 & Use-between & -11 & 22 & 100 & 09 & 22 & 16 & 24 & 05 & 23 & 00 & -31 \\
4 & Use-within & 62 & 13 & 09 & 100 & -28 & -18 & 35 & -01 & -12 & -16 & 37 \\
5 & Comfort & -18 & 30 & 22 & -28 & 100 & 60 & 16 & 39 & 18 & 21 & -29 \\
6 & Citizenship & -02 & 21 & 16 & -18 & 60 & 100 & 10 & 09 & 23 & 13 & -28 \\
7 & Conscientiousness & 10 & 41 & 24 & 35 & 16 & 10 & 100 & -12 & 13 & 15 & 45 \\
8 & Self-monitoring & -35 & 40 & 05 & -01 & 39 & 09 & -12 & 100 & -02 & 19 & 39 \\
9 & Rating level & -23 & 26 & 23 & -12 & 18 & 23 & 13 & -02 & 100 & -40 & -50 \\
10 & Discrimination - ratees & 05 & 08 & 00 & -16 & 21 & 13 & 15 & 19 & -40 & 100 & -13 \\
11 & Discrimination - dimensions & 12 & 17 & -31 & 37 & -29 & -28 & 45 & 39 & -50 & -13 & 100 \\
\hline
\end{tabular}

Decimals are omitted.

third region occupied mainly by the organization/system-related variables.

\section{DISCUSSION}

On the whole, the findings of the present study provide empirical support for the veracity of the mapping sentence, relating rater attitudinal, and dispositional (personality) factors with rating behavior.

Specifically, our results suggest, as in previous investigations and publications (e.g., Tziner et al., 1998, 2001; Tziner and Roch, 2016), that attitudes and beliefs regarding performance appraisal systems and rater personality qualities are relevant factors likely to relate to high (positive) vs. low (negative) rating behaviors. For example, in regard to ratee discrimination, this implies that the rater discriminates between ratees of high vs. low levels of performance by according high ratings to the former and low ratings to the latter. It also emerges from Figure 1 that there is no order between the regions; namely, the rater, the rate, and the organization/system play equal roles in explaining the structure of the considerations and qualities affecting rating behavior. Unlike the study by Tziner et al. (2001), here we cannot conclude that certain factors are more proximal to the task of performance rating than other; all seem to be equally proximal. It is possible that the facet analytic approach helps to discern findings, which remain hidden when linear analytical methods, such as regression analyses, are used.

However, we cannot exclude the possibility that the present results differ from previous findings because of cultural differences. The data in the present investigation were collected from Israeli respondents, whereas previous studies primarily examined North American respondents. Nonetheless, it could well be that the structure generalizes across cultures as it was demonstrated in a study that explored cross-cultural values structure using the facet analytic approach along with the SSA procedure (Gouveia et al., 2015).

We suggest that in order to test the generalizability of the present findings, future studies should be pursued using respondents from various organizations, cultures and organizational strata. Moreover, efforts should directed to exploring whether each facet plays a different role (e.g., modulating, polarizing), and whether the combined interaction results in a defined structure (e.g., radix, conex). The theoretical and practical implications of such structures should be explored.

In summary, the present findings appear encouraging in that they provide clear evidence of the structure of relationships between rater attitudes and beliefs about performance, rater personality qualities, and rating behavior. As such, this study paves the way for further investigations aimed at extending and expanding our understanding of this issue. Likewise, our current study demonstrates as in other OB/HRM investigations, such as the exploration of the coping with stress strategies (Rabenu et al., 2015) and the career span of principal's self-efficacy (Fisher, 2015), that the facet analytic approach along with its statistical tools (e.g., SSA, POSAC) is very instrumental in revealing insights unavailable with other commonly used methodological and statistical procedures.

\section{AUTHORS' NOTE}

The authors wish to thank Gil Sharoni for his help in collecting and analyzing data. and to Professors Kevin R. Murphy and Jeanette N. Cleveland for help with the conception of the theoretical foundation and research instruments.

An earlier version of this paper was presented at the Facet Theory Association Congress.

No ethics review process is needed for survey studies in Israel (both at the national and institutional levels); only in cases where experimental studies with human subjects are pursued such an approval is required.

\section{AUTHOR CONTRIBUTIONS}

All authors listed, have made substantial, direct and intellectual contribution to the work, and approved it for publication. 


\section{REFERENCES}

Bandura, A. (1977). Social Learning Theory. Englewood Cliffs, NJ: Prentice Hall. Bandura, A. (1982). Self-efficacy mechanisms in human agency. Am. Psychol. 37, 122-147. doi: 10.1037/0003-066X.37.2.122

Barrick, M. R., and Mount, M. K. (1991). The big five personality dimensions and job performance: a meta-analysis. Pers. Psychol. 44, 1-26. doi: 10.1111/j.1744-6570.1991.tb00688.x

Bernardin, H. J., and Orban, J. (1985). "Leniency effect as a function of rating format, purpose for appraisal and individual differences," in Presented at the Annual Meeting of the Academy of Management, Boston, MA.

Bolino, M. C. (1999). Citizenship and impression management: good soldiers or good actors? Acad. Manag. Rev. 24, 82-98.

Canter, D. (ed.). (1985). Facet Theory Approaches to Social Research. New York, NY: Springer.

Cleveland, J. N., and Murphy, K. R. (1992). "Analysis of performance appraisal as goal-directed behavior," in Research in Personnel and Human Resource Management, Vol. 10, eds G. Ferris and K. Rowland (Greenwich, CT: JAI Press), 121-185.

Cleveland, J. N., Murphy, K. R., and Williams, R. E. (1989). Multiple uses of performance appraisal: prevalence and correlates. J. Appl. Psychol. 74, 130-135. doi: 10.1037/0021-9010.74.1.130

Costa, P. T., and McCrae, R. R. (1992). Revised NEO Personality Inventory and the NEO Five-Factor Inventory. Odessa, FL: Psychological Assessment Resources.

Elizur, D. (1984). Facet of work values: a structural analysis of work outcomes. J. Appl. Psychol. 9, 379-390. doi: 10.1037/0021-9010. 69.3.379

Fisher, Y. (2015). "The wave syndrom: a career span of principals' self-efficacy," in Facet Theory: Searching for Structure in Complex Social,Cultural and Psychological Phenomena, eds A. Roazzi, B. Campello de Souza, and W. Bilsky, (Recife: UFPE), 198-216.

Frayne, C. A., and Latham, G. P. (1987). Application of social training theory to employer self-management of attendance. J. Appl. Psychol. 72, 387-392. doi: 10.1037/0021-9010.72.3.387

Fried, Y., Tiegs, R. B., and Bellamy, A. R. (1992). Personal and interpersonal predictors of supervisors' avoidance of evaluating subordinates. J. Appl. Psychol. 77, 462-468. doi: 10.1037/0021-9010.77.4.462

Gangestad, S., and Snyder, M. (1985). To carve nature at its joints: on the existence of discrete classes in personality. Psychol. Rev. 92, 317-349. doi: 10.1037/0033-295X.92.3.317

Gouveia, V. V., Nunes da Fonseca, P., Mendes do Nascinto, D. A., de Souza Filho, J. F., and Guerra, V. V. (2015). "Cross cultural valueas: evidence of adequacy and equivalence," in Facet Theory: Searching for Structure in Complex Social, Cultural and Psychological Phenomena, eds A. Roazzi, B. Campello de Souza, and W. Bilsky (Recife: UFPE).

Guttman, L. (1959). A structural theory of intergroups, beliefs and actions. Am. Sociol. Rev. 24, 318-328. doi: 10.2307/2089380

Hackett, M. W. (2014). Facet Theory and the Mapping Sentence: Evolving Philosophy, Use and Application. New York, NY: Palgrave Macmillan.

Jawahar, I. M., and Stone, T. H. (1997). Appraisal purpose versus perceived consequences and rater self-monitoring on leniency of ratings and decisions. Res. Pract. Hum. Res. Manag. 5, 39-54.

Landy, F. J., and Farr, J. L. (1992). The Measurement of Work Performance. New York, NY: Academic Press.

Murphy, K. R. (2008). Explaining the weak relationship between job performance and ratings of job performance. Ind. Organ. Psychol. 1, 148-160. doi: 10.1111/j.1754-9434.2008.00030.x

Murphy, K. R., and Cleveland, J. N. (1991). Performance Appraisal: An Organizational Perspective. Boston, MA: Allyn \& Bacon.
Murphy, K. R., and Cleveland, J. N. (1995). Understanding Performance Appraisal: Social, Organizational, and Goal-based Perspectives. Thousand Oaks, CA: Sage Publications.

Napier, N., and Latham, G. P. (1986). Outcome expectancies of people who conduct performance appraisals. Pers. Psychol. 39, 827-837.

Organ, D. W. (1988). Organizational Citizenship Behavior: The Good Soldier Syndrome. Lexington, MA: Lexington Books.

Podaskoff, P. M., and MacKenzie, S. B. (1989). A Second-Generation Measure Organizational Citizenship Behavior. Bloomington, IN: Indiana University.

Rabenu, E., Elizur, D., and Yaniv, E. (2015). "The structure of coping with stress: comparison between SSA and factor analysis," in Facet Theory: Searching for Structure in Social, Cultural and Psychological Phenomena, eds A. Roazzi, B. Campello de Souaza, and W. Bilsky (Recife: Editura UFPE), 167-182.

Roazzi, A., Campello de Soura, B., and Bilsky, W. (2015). Facet Theory: Searching for Structure in Complex Social, Cultural and Psychological Phenomena. Recife: UFPE.

Shye, S., Elizur, D., and Hoffman, M. (1994). Introduction to facet theory: content design and intrinsic data analysis in behavioral research. Applied Social Research Methods Series v. 35. (Thousand Oaks, CA: Sage Publications), 187. doi: 10.4135/9781412984645

Steers, R. M., and Lee, T. W. (1983). "Facilitating effective performance appraisals: the role of employee commitment and organizational climate," in Performance Measurement and Theory, eds. F. Landy, S. Zedeck, and J. N. Cleveland (Hillsdale, MI: LawrenceErlbaum Associates), 75-88.

Tziner, A., and Murphy, K. (1999). Additional evidence of attitudinal influences in performance appraisal. J. Bus. Psychol. 13, 407-419. doi: $10.1023 / \mathrm{A}: 1022982501606$

Tett, R. P., Jackson, D. N., and Rothstein, M. (1991). Personality measures as predictors of job performance: a Meta-analytic review. Pers. Psychol. 44, 703-742. doi: 10.1111/j.1744-6570.1991.tb00696.x

Tziner, A. (1987). The Facet Analytic Approach to Research and Data Processing. New York, NY: Verlag-Peter-Lang.

Tziner, A., Murphy, K. R., and Cleveland, J. N. (2001). Relationships between attitudes toward organization and performance appraisal systems and rating behavior. Int. J. Sel. Assess. 9, 226-239. doi: 10.1111/1468-2389.00176

Tziner, A., Murphy, K. R., and Cleveland, J. N. (2002). Does conscientiousness moderate the relationship between attitudes and beliefs regarding performance appraisal rating behavior? Int. J. Sel. Assess. 10, 218-224.

Tziner, A., Murphy, K. R., Cleveland, J. N., Beaudin, G., and Marchand, S. (1998). Impact of rater beliefs regarding performance appraisal and its organizational context on appraisal quality. J. Bus. Psychol. 12, 457-467. doi: 10.1023/A:1025003106150

Tziner, A., and Roch, S. G. (2016). Disappointing interventions and weak criteria: carving out a solution is still possible. Ind. Organ. Psychol. 9, 350-356. doi: 10.1017/iop.2016.24

Villanova, P., Bernardin, J. H., Dahmus, S. A., and Sims, R. (1993). Rater leniency and performance appraisal discomfort. Educ. Psychol. Meas. 53, 789-798. doi: $10.1177 / 0013164493053003023$

Conflict of Interest Statement: The authors declare that the research was conducted in the absence of any commercial or financial relationships that could be construed as a potential conflict of interest.

Copyright (ㅇ) 2017 Tziner and Levy. This is an open-access article distributed under the terms of the Creative Commons Attribution License (CC BY). The use, distribution or reproduction in other forums is permitted, provided the original author(s) or licensor are credited and that the original publication in this journal is cited, in accordance with accepted academic practice. No use, distribution or reproduction is permitted which does not comply with these terms. 